\title{
Calibration algorithm for both amplitude and phase of full-polarimetric SAR data
}

\section{フル偏波 SAR データの振幅及び位相の校正手法}

\author{
Nobuhiko KADOWAKI, Ikuo ARAI and Bunkei MATSUSHITA \\ 門脇 信彦*・荒井 郁男**・松下 文経***
}

\begin{abstract}
The utility of PALSAR polarimetric mode data has a high potential for forest biomass estimation. However, it is necessary to calibrate the polarimetric SAR data both in terms of amplitude and phase for this purpose. Therefore, we emphasized the phase calibration and expanded the application of Klein's algorithm to the general calibration site in this paper. A method for extracting the pixels from the observed image to satisfy the assumptions of Klein's algorithm was also developed. In addition, Faraday rotation is compensated for as the remainder of distortion of the transmission path included in the polarization impurity and channel imbalance in the SAR system. One frame of the JPL/AIRSAR L-band polarimetric mode image was used to evaluate the calibration method. Two known trihedral corner reflectors were deployed on the pasture land in the image. Using this grass site, we obtained an acceptable result for the calibration.
\end{abstract}

和文摘要：PALSARのフル偏波モードデータが, 森 林バイオマスの推定には非常に有望である。このため, ポーラリメトリック SAR データの振幅と位相の両方 の情報が必要となり,これらの校正が求められている。 従って, 本論文は位相校正に重点を置く。また Klein ア ルゴリズムの仮定条件を満たす為のピクセル抽出手法 を開発することにより, Klein アルゴリズムを草地など 一般的な校正サイトにも適用できるように拡張した。 さらに伝達経路上の歪であるファラディ回転はアンテ 十起因の歪と見做し, SAR システムノイズの一部とし て補正される。最後に JPL/AIRSAR L バンドのフル偏 波モードデータ 1 フレームを利用して，校正手法を評

* 三菱マテリアル資源開発株式会社

Mitsubishi Materials Natural Resources Development Corp.

厂330-0835 埼玉県さいたま市大宮区北袋町一丁目297 番地

** 電気通信大学電子工学科

Electronics Engineering Department, The University of Electro-communications

***筑波大学大学院生命環境科学研究科

Graduate School of Life and Environmental Sciences, University of Tsukuba

「写真測量とリモートセンシング」VOL. 46，NO. 1，2007
価した結果, 予め牧草地に設置された 2 台の三面コー ナーリフレクタから校正方法の妥当性が確認された。

\section{Introduction}

The Advanced Land Observing Satellite (ALOS), called "Daichi," was launched on January 24, 2006. The initial full polarimetric image was successfully acquired from the Phased Array type L-band Synthetic Aperture Radar (PALSAR) onboard the Daichi. The full polarimetric system requires that data from the four polarization-diverse channels (i.e. $\mathrm{HH}, \mathrm{HV}, \mathrm{VH}$ and $\mathrm{VV}$ polarization) and the proper amplitude and phase weights are also needed to determine the polarization states synthetically. Yamada et al. (2001) proposed a numerical solution technique based on the ESPRIT (estimation of signal parameters via rotational invariance techniques) method for forest biomass analysis that involves the concept of polarimetric SAR interferometry (Pol-InSAR, Cloude and Papathannassou, 1998). The phase is a key parameter for the interferometry process in their method. Therefore, it is 
necessary to carefully calibrate both the amplitude and phase of PALSAR for four individual channels. However, the existing methods can not save the phase completely (e.g. POLCAL algorithm, van Zyl et al. 1990).

Several approaches were proposed to calibrate polarimetric SAR data in the 1990s (Freeman, 1992). In these approaches, the POLCAL (Polarimetric Calibration) algorithm, which was designed to process compressed JPL (Jet Propulsion laboratory) Stokes matrix data, is known as the formal algorithm for polarimetric SAR data calibration at JPL. The POLCAL implemented its own symmetrization of the scattering matrix to reduce the volume of data. Consequently, the initial phase information was ignored in the POLCAL (van $\mathrm{Zyl}$ et al., 1990). In contrast, Klein's algorithm (Klein, 1992) is an approach based on the scattering matrix, and thus contains complete phase information. Therefore, Klein's algorithm has the potential to calibrate both amplitude and phase for full-polarimetric SAR data.

In addition, the Faraday rotation also distorts the measurements of space-borne L-band SARs, such as PALSAR, an issue that has been addressed by Freeman (Freeman et al., 2004a). The phase terms of L-band data have been rotated with a Faraday rotation angle $\Omega$, which was estimated to be $40^{\circ}$ for the largest value through the ionosphere at daytime. Therefore, the Faraday rotation should also be compensated for PALSAR data.

Moreover, the PALSAR is a polar orbit satellite SAR system. Thus a calibration site spread out in a nearly east-west direction should be chosen. However, several known ideal calibration sites, such as the dry lake bed of Goldstone in the USA, are spread in a north-south orientation, and thus can not be used for PALSAR calibration. Therefore, an alternative calibration site should be found for the purpose of PALSAR calibration.

Recently, a retrodirective polarimetric active radar calibrator (PARC) was developed for PALSAR calibration (Fujita, 2003). A polarimetric cali- bration method for satellite SAR data subject to Faraday rotation was also proposed using three artificial targets (Fujita, 2005). However, in these papers, the initial phase was not discussed.

Therefore, the major objective of the present paper was to describe a method for calibrating the amplitude and phase of polarimetric SAR data based on Klein's algorithm. In addition, the method of Faraday rotation compensation was also incorporated. AIRSAR data, which share similar characteristics with PALSAR data, were used to test the proposed calibration method in this paper.

\section{Methodology}

\subsection{Theory of Calibration}

The transmitting and receiving phase paths of the polarimetric SAR system were modeled by Zebker and Lou (1990). The polarimetric calibration factors are as follows :

Observed matrix : $O_{i j}\left(O_{h v} \neq O_{v h}\right)$

Ideal scattering matrix : $S_{i j}\left(S_{h v}=S_{v h} \neq 0\right)$

Distortion of transmit : $t_{i j}$ (function of range pixel)

Distortion of receive : $r_{i j}$ (function of range pixel)

System thermal noise : $n_{i j}$ (known or ignoring) Thus, the calibration formulation can be written as:

$$
\begin{aligned}
& \left(\begin{array}{ll}
O_{h h} & O_{h v} \\
O_{v h} & O_{v v}
\end{array}\right)=\left(\begin{array}{ll}
t_{h h} & t_{h v} \\
t_{v h} & t_{v v}
\end{array}\right)\left(\begin{array}{ll}
S_{h h} & S_{h v} \\
S_{v h} & S_{v v}
\end{array}\right)\left(\begin{array}{ll}
r_{h h} & r_{v h} \\
r_{h v} & r_{v v}
\end{array}\right) \\
& +\left(\begin{array}{ll}
n_{h h} & n_{h v} \\
n_{v h} & n_{v v}
\end{array}\right)
\end{aligned}
$$

Assuming that the diagonal elements of the $t_{i j}$ and $r_{i j}$ matrixes are non-zero, and ignoring the noise, equation (1) can be rewritten as:

$$
\begin{gathered}
\left(\begin{array}{cc}
O_{h h}^{\prime} & O_{h v}^{\prime} \\
O_{v h}^{\prime} & O_{v v}^{\prime}
\end{array}\right)=A e^{j \phi}\left(\begin{array}{cc}
1 & \tilde{t}_{h v} \\
\tilde{t}_{v h} & 1
\end{array}\right)\left(\begin{array}{ll}
1 & 0 \\
0 & \tilde{t}_{v v}
\end{array}\right)\left(\begin{array}{ll}
S_{h h} & S_{h v} \\
S_{v h} & S_{v v}
\end{array}\right) \\
\left(\begin{array}{ll}
\tilde{r}_{h h} & 0 \\
0 & 1
\end{array}\right)\left(\begin{array}{cc}
1 & \tilde{r}_{v h} \\
\tilde{r}_{h v} & 1
\end{array}\right)
\end{gathered}
$$

where $\quad \tilde{t}_{h v}=t_{h v} / t_{v v}, \quad \tilde{t}_{v h}=t_{v h} / t_{h h}, \quad \tilde{t}_{v v}=t_{v v} / t_{h h}, \quad \tilde{r}_{h v}=$ $r_{h v} / r_{v v}, \tilde{r}_{v h}=r_{v h} / r_{h h}, \tilde{r}_{h h}=r_{h h} / r_{v v}$ and $A e^{j \phi}=t_{h h} r_{v v}$.

By rewriting $t_{i j}$ and $r_{i j}$ in equation (2), the radar system distortion is separated into three components (seven factors) as follows: 


\section{1) Polarization impurity}

Transmit factors : $\tilde{t}_{h v}, \tilde{t}_{v h}$ (two complex numbers)

Receive factors: $\tilde{r}_{h v}, \tilde{r}_{v h}$ (two complex numbers)

2 ) Channel imbalance

Transmit factors: $\tilde{t}_{v v}$ (one complex number)

Receive factors: $\tilde{r}_{h h}$ (one complex number)

3 ) Absolute gain error

Transmit-receive factors: $A e^{j \phi}$ (one complex number)

\subsection{Klein's algorithm}

Detailed descriptions of all information can be found in Klein (1992). We focus our attention on the problems of the assumption condition and the processing procedure. Three calibrations were implemented as follows.

\subsubsection{Cross-talk calibration}

The first process is the estimation and removal of polarization impurity. The remaining error source is due to imperfections in the radar antenna itself, which result in impure polarization states in the individual polarization combinations measured directly by SAR.

We choose the flat areas from the image in order to estimate $\tilde{t}_{h v}$. In these areas, the following assumptions should be satisfied:

1) Backscatter reciprocal $\left(S_{v h}=S_{h v}\right)$ for all pixels used to estimate $\tilde{t}_{h v}$;

2 ) A nonlinear relationship exists among the $S_{h h}$, $S_{h v}$ and $S_{v v}$ terms;

3) $\tilde{t}_{h v}$ is computed from the areas containing azimuthally distributed symmetric natural targets. The $\mathrm{co}^{-}$and cross-polarized components of the $S_{i j}$ matrix are uncorrelated, i.e.

$\varepsilon\left(S_{h h} S_{h v}^{*}\right)=\varepsilon\left(S_{v v} S_{h v}^{*}\right)=\varepsilon\left(S_{h h} S_{v h}^{*}\right)=\varepsilon\left(S_{v v} S_{v h}^{*}\right)=0 ;$

Here, $\varepsilon(x)$ is the ensemble average of $x$, which in terms of image parameters over an extended area.

4) The systemic noise is independent of the signals, and it can be previously determined or is small enough that it can be neglected.

To satisfy assumption 2), we should avoid select- ing stratified geological formations or expanses of water, because they show a linear relationship between the $S_{h h}$ and $S_{v v}$ terms (Klein, 1992). Therefore, it is important to ensure that the selected pixels are satisfactory. The JPL Goldstone calibration site, which is enough flat and vegetation-free, is a special ideal case for calibration (Klein, 1992). However, in general, we should find pixels in any area where the aforementioned assumptions can be satisfied. The selected pixels will affect the calibration accuracy directly.

The outlines of Cross-talk calibration are as follows :

1) Pick an area that is relatively homogeneous and has vegetation cover as little as possible. In order to obtain good statistics, the area should be as large as possible.

2 ) Select pixels that satisfy the above four assumptions.

3 ) Calculate the average covariance matrix of the selected pixels.

4 ) Calculate the eigenvalue and eigenvector of the average covariance matrix.

5 ) Use the first eigenvector corresponding to the minimum eigenvalue to obtain the initial $\left|S_{v h}\right|^{2}$.

6 ) Repeat steps 1)-5) until the value of $\left|S_{v h}\right|^{2}$ reaches a stable solution.

7 ) Solve, $\rho \approx 1 / \tilde{r}_{h h} \tilde{t}_{v v}, \tilde{t}_{h v}, \tilde{t}_{v h}, \tilde{r}_{v h}$ and $\tilde{r}_{h v}$.

\subsubsection{Co-channel imbalance calibration}

The scattering matrix of an ideal trihedral corner reflector is as follows :

$S^{t r i}=\sqrt{\sigma}\left(\begin{array}{ll}1 & 0 \\ 0 & 1\end{array}\right)$.

where the $\sigma$ is the backscattering cross section. Combining equation (3) with equation (2), the scattering matrix of the observed trihedral corner reflector can be written as :

$O^{t r i}=\sqrt{\sigma} r_{v v} t_{h h}\left(\begin{array}{ll}\tilde{r}_{h h}+\tilde{r}_{h v} \tilde{t}_{h v} \tilde{t}_{v v} & \tilde{r}_{v h} \tilde{r}_{h h}+\tilde{t}_{h v} \tilde{t}_{v v} \\ \tilde{t}_{v h} \tilde{r}_{h h}+\tilde{r}_{h v} \tilde{t}_{v v} & \tilde{t}_{v v}+\tilde{r}_{v h} \tilde{t}_{v h} \tilde{r}_{h h}\end{array}\right)$

Ignoring the third-order terms of equation (4), we have : 
$O^{t r i} \approx \sqrt{\sigma} r_{v v} t_{h h}\left(\begin{array}{cc}\tilde{r}_{h h} & \tilde{r}_{v h} \tilde{r}_{h h}+\tilde{t}_{h v} \tilde{t}_{v v} \\ \tilde{t}_{v h} \tilde{r}_{h h}+\tilde{r}_{h v} \tilde{t}_{v v} & \tilde{t}_{v v}\end{array}\right)$

(5)

Dividing $O_{h h}^{t r i}$ by $O_{v v}^{t r i}$ and substituting $\rho \approx 1 / \tilde{r}_{h h} \tilde{t}_{v v}$ for equation (5), we can obtain :

$\therefore \quad \tilde{r}_{h h} \approx \pm \sqrt{\frac{O_{h h}^{t r i}}{\rho O_{v v}^{t r i}}}, \tilde{t}_{v v} \approx \frac{1}{\rho \tilde{r}_{h h}}$

where $\rho \approx 1 / \tilde{r}_{h h} \tilde{t}_{v v}$, obtained from the cross-talk calibration.

\subsubsection{Radiometric calibration}

Substituting the observed $O^{t r i}$, the cross-section $\sigma$ of the trihedral corner reflector, $\tilde{r}_{h h}, \tilde{t}_{v v}, \tilde{r}_{h v}, \tilde{r}_{v h}, \tilde{t}_{h v}$ and $\tilde{t}_{v h}$ in equation (2), we can obtain the $A e^{j \phi}$ term straightforwardly.

\subsection{Compensation for Faraday rotation}

Faraday rotation is a phenomenon by which a linearly polarized wave passing through the ionosphere can have its plane of polarization rotated. Lband polarimetric waves of PALSAR may be affected while the polarized wave propagates through the plasma (Freeman et al., 2004a).

A polarimetric SAR data calibration model that takes into account Faraday rotation has been proposed by Freeman (2004b). Ignoring the system noise, we can obtain :

$$
\begin{gathered}
\left(\begin{array}{cc}
O_{h h}^{\Omega} & O_{h v}^{\Omega} \\
O_{v h}^{\Omega} & O_{v v}^{\Omega}
\end{array}\right)=A e^{j \phi}\left(\begin{array}{cc}
1 & \delta_{2} \\
\delta_{1} & 1
\end{array}\right)\left(\begin{array}{ll}
1 & 0 \\
0 & f_{1}
\end{array}\right)\left(\begin{array}{cc}
\cos \Omega & \sin \Omega \\
-\sin \Omega & \cos \Omega
\end{array}\right) \\
\left(\begin{array}{ll}
s_{h h} & s_{h v} \\
s_{v h} & s_{v v}
\end{array}\right)\left(\begin{array}{cc}
\cos \Omega & \sin \Omega \\
-\sin \Omega & \cos \Omega
\end{array}\right)\left(\begin{array}{ll}
1 & 0 \\
0 & f_{2}
\end{array}\right)\left(\begin{array}{cc}
1 & \delta_{3} \\
\delta_{4} & 1
\end{array}\right)
\end{gathered}
$$

where $\Omega$ is the Faraday rotation angle. Multiplying the three matrices on the left and right sides of the $S_{i j}$ matrix, we obtain:

$$
\begin{aligned}
& \left(\begin{array}{cc}
1 & \delta_{2} \\
\delta_{1} & 1
\end{array}\right)\left(\begin{array}{ll}
1 & 0 \\
0 & f_{1}
\end{array}\right)\left(\begin{array}{cc}
\cos \Omega & \sin \Omega \\
-\sin \Omega & \cos \Omega
\end{array}\right) \\
& =\left(\begin{array}{ll}
\cos \Omega-\delta_{2} f_{1} \sin \Omega & \sin \Omega+\delta_{2} f_{1} \cos \Omega \\
\delta_{1} \cos \Omega-f_{1} \sin \Omega & \delta_{1} \sin \Omega+f_{1} \cos \Omega
\end{array}\right)
\end{aligned}
$$

$$
\begin{aligned}
& \left(\begin{array}{cc}
\cos \Omega & \sin \Omega \\
-\sin \Omega & \cos \Omega
\end{array}\right)\left(\begin{array}{ll}
1 & 0 \\
0 & f_{2}
\end{array}\right)\left(\begin{array}{cc}
1 & \delta_{3} \\
\delta_{4} & 1
\end{array}\right) \\
& =\left(\begin{array}{ll}
\cos \Omega-\delta_{4} f_{2} \sin \Omega & \delta_{3} \cos \Omega+f_{2} \sin \Omega \\
\sin \Omega-\delta_{4} f_{2} \cos \Omega & \delta_{3} \sin \Omega+f_{2} \cos \Omega
\end{array}\right)
\end{aligned}
$$

Combining equations (8) and (9) with equation (7), we can rewrite the right side of (7) as follows:

$\left(\begin{array}{cc}O_{h h}^{\Omega} & O_{h v}^{\Omega} \\ O_{v h}^{\Omega} & O_{v v}^{\Omega}\end{array}\right)=A e^{j \phi}\left(\begin{array}{cc}t_{h h}^{\Omega} & t_{h v}^{\Omega} \\ t_{v h}^{\Omega} & t_{v v}^{\Omega}\end{array}\right)\left(\begin{array}{ll}s_{h h} & s_{h v} \\ s_{v h} & s_{v v}\end{array}\right)\left(\begin{array}{cc}r_{h h}^{\Omega} & r_{v h}^{\Omega} \\ r_{v h}^{\Omega} & r_{v v}^{\Omega}\end{array}\right)$

When equation (10) is compared with equation (1), it can be seen that (10) is identical to (1) except for the noise term. As with equation (1), we can expand (10) as follows:

$$
\begin{gathered}
\left(\begin{array}{ll}
O_{h h}^{\Omega} & O_{h v}^{\Omega} \\
O_{v h}^{\Omega} & O_{v v}^{\Omega}
\end{array}\right)=A A^{\Omega} e^{j\left(\phi+\phi^{\Omega}\right)}\left(\begin{array}{cc}
1 & \tilde{t}_{h v}^{\Omega} \\
\tilde{t}_{v h}^{\Omega} & 1
\end{array}\right)\left(\begin{array}{ll}
1 & 0 \\
0 & \tilde{t}_{v v}^{\Omega}
\end{array}\right) \\
\left(\begin{array}{ll}
S_{h h} & S_{h v} \\
s_{v h} & S_{v v}
\end{array}\right)\left(\begin{array}{cc}
\tilde{r}_{h h}^{\Omega} & 0 \\
0 & 1
\end{array}\right)\left(\begin{array}{cc}
1 & \tilde{r}_{v h}^{\Omega} \\
\tilde{r}_{h v}^{\Omega} & 1
\end{array}\right)
\end{gathered}
$$

Because equation (11) has the same expression as equation (2), we can consider the effect of Faraday rotation to be the remainder of distortion of the transmission path included in the polarization impurity and channel imbalance. Consequently, Klein's algorithm can also be used to calibrate the polarimetric SAR data that contain a Faraday rotation angle $\Omega$. In order to obtain the factors of polarimetric calibration only, it is not necessary to determine the value of the angle $\Omega$. A similar result was shown by Kimura (2005).

\subsection{Extracting the pixels to satisfy the assump- tions}

A flow chart of the calibration processes is shown in Figure 1. To satisfy assumptions (2) and (3) of section 2.2.1, we derived three rules for extracting the pixels from the observed image, as follows.

1) To select the flat surface pixels, three maximum thresholds of the $\mathrm{HH}^{-}, \mathrm{HV}^{-}$and $\mathrm{VV}^{-}$polarized magnitudes were determined and were labeled $\alpha, \beta$ and $\gamma$, respectively.

2) A minimum threshold $\omega$ of the nonlinear rela- 
tionship was also determined to satisfy assumption (2).

3 ) To satisfy assumption (3), a maximum threshold $\tau$ within a moving $7 \times 7$ window box was determined.

The above five thresholds depend on observed SAR data. The processes of calibration were implemented repetitively until the smallest $d B\left(S_{h v}^{t r i} /\right.$

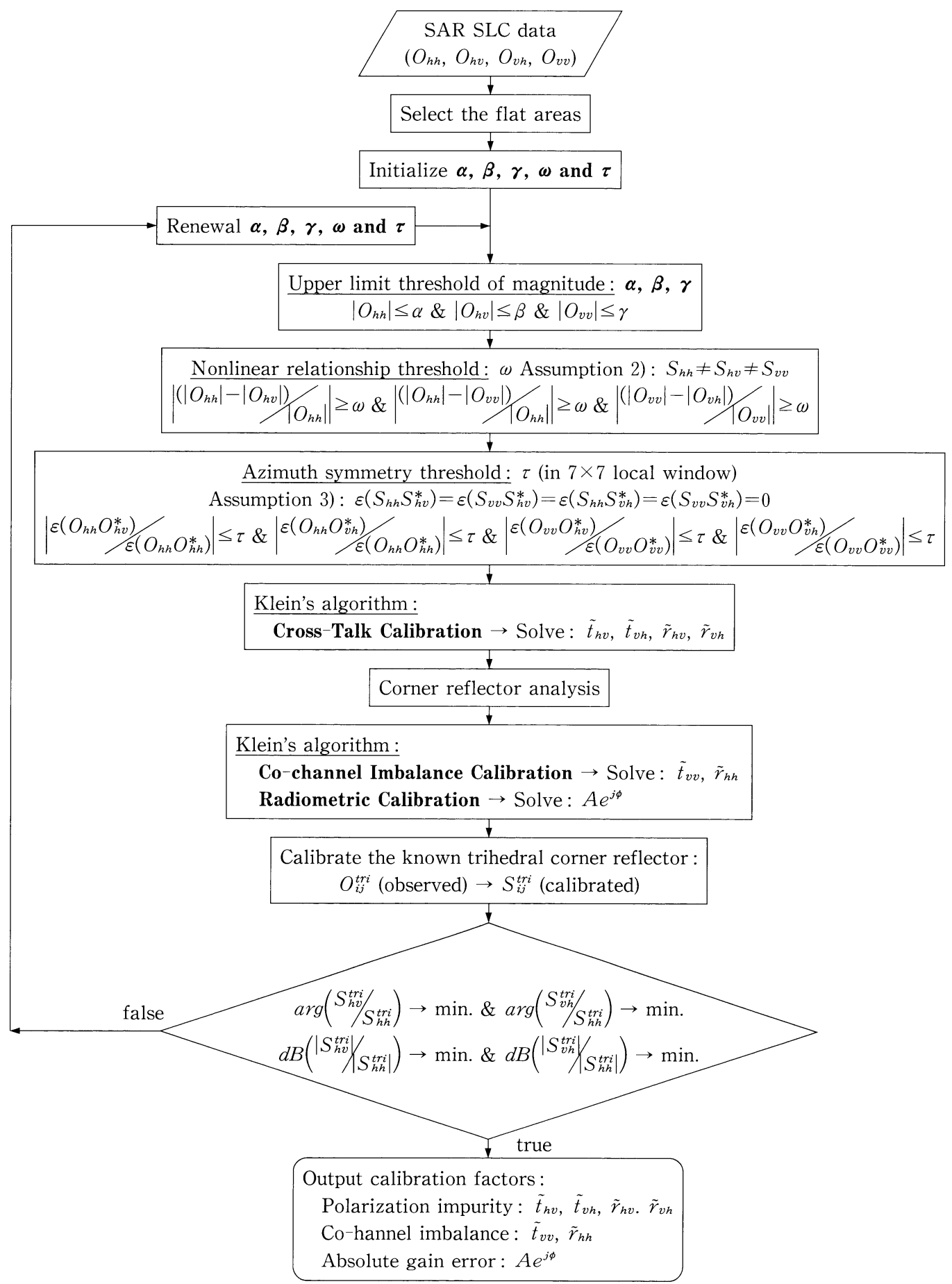

Figure 1 Flowchart of the calibration process. 
$\left.S_{h h}^{t r i}\right)$ and $\arg \left(S_{h v}^{t r i} / S_{h h}^{t r i}\right)$ for the calibrated scattering matrix of the known trihedral corner reflector were obtained. The aforementioned seven calibration factors were then estimated.

\section{Data}

A scene of the Ouachita Mountains in Arkansas in the USA, made with JPL/AIRSAR (L-band polarimetric mode SAR image) single-look complex data collected on July 21, 1990, was used to test the calibration method proposed in this paper. The slant range and azimuth sample spacing were 6.662 meters and 3.03 meters, respectively. Figure 2 (a) shows a total power image of 1024 pixels in azimuth by 750 lines in range direction. Two trihedral corner reflectors with $2.0 \mathrm{~m}$ sides, named CR_1 and CR_2, were deployed on the pasture land. The ratio of the HH-polarized signal of CR_1 (Figure 2 (b)) to the pasture background was $28.51 \mathrm{~dB}$ (Figure 2 (c)).

\section{Results}

To determine the maximum and minimum thresh- olds for satisfying assumptions (2) and (3) in section 2.2.1, we picked out twelve areas delineated by dashed line rectangles in the SAR image to obtain a better statistical average (Figure 2 (a)). A total of 1756 pixels for CR_1 and 11848 pixels for CR_2 were extracted from the above twelve areas, respectively. The determined maximum $(\alpha, \beta, \gamma$ and $\tau)$ and minimum thresholds $(\omega)$ from the extracted pixels for CR_1 and CR_2 are shown in Table 1. It is noted that the thresholds of $\alpha, \beta$ and $\gamma$ were very different between CR_1 and CR_2, even though both CR_1 and CR_2 are two ideal trihedral corner reflectors. This is because of the different distances between the SAR antenna and the two trihedral corner reflectors. The other two thresholds, $\omega$ and $\tau$, were almost the same for CR_1 and CR_2. In Table 1, the local incidence angle of CR_ 1 was $53.09^{\circ}$, close to the boresight angle of $54.74^{\circ}$. Therefore the response of CR_1 was higher than that of CR_2, even though CR_1 was farther from the SAR antenna than CR_2.

Table 2 shows the estimated seven calibration factors for CR_1 and CR_2 based on the above thresholds. It should also be noted that these calibration factors were also different between CR_1 and

(a) JPL/AIRSAR L-band SLC Total Power Image (1990/07/21)

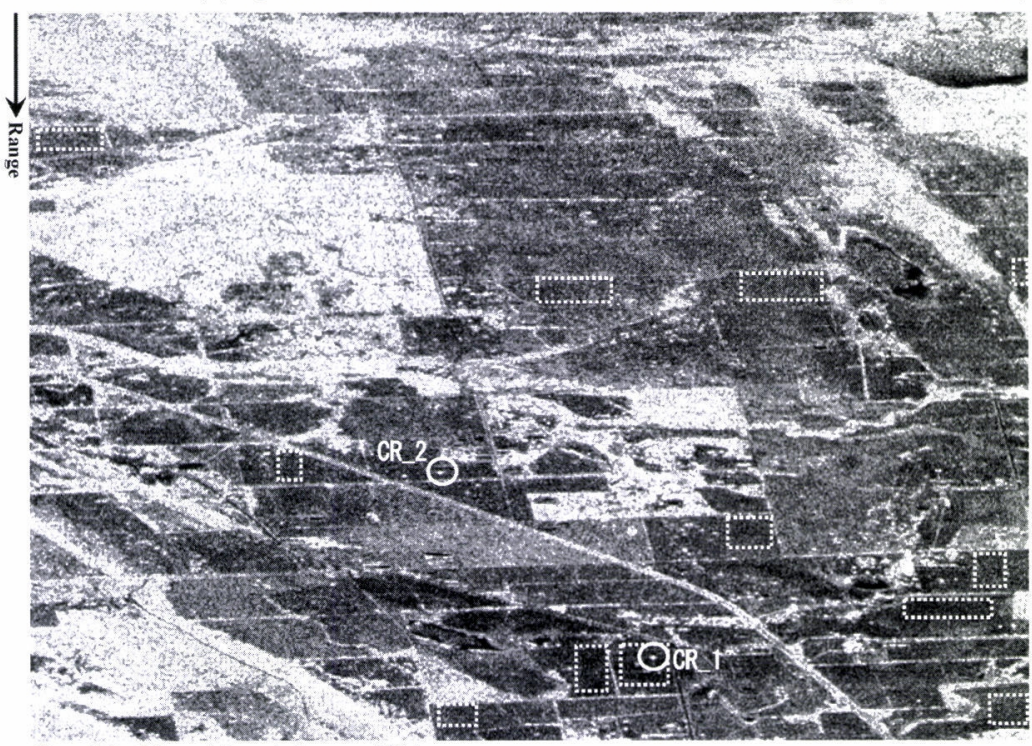

Ouachita Mountains, Arkansas USA.

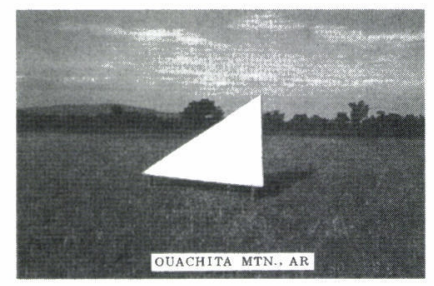

(b) A trihedral corner reflector (CR 1) with $2 \mathrm{~m}$ sides.

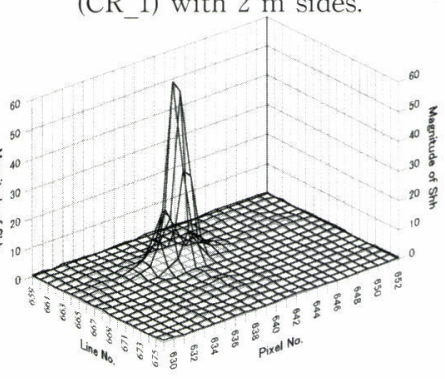

(c) CR_1 response $=28.51 \mathrm{~dB}$. $\left(S_{\text {hh }}\right.$ vs. background $)$

Figure 2 AIRSAR L-band total power image and a response of trihedral corner reflector CR_1. 
Table 1. The responses and thresholds of the two known trihedral corner reflectors.

\begin{tabular}{lcc}
\hline Responses \& thresholds & CR_1 & CR_2 \\
\hline Local incidence angle* & $53.09^{\circ}$ & $48.33^{\circ}$ \\
$\left|S_{h h}\right|$ response vs. background & $28.51 \mathrm{~dB}$ & $26.10 \mathrm{~dB}$ \\
Upper limit threshold $\alpha$ & 1.2 & 2.5 \\
Upper limit threshold $\beta$ & 0.3 & 0.5 \\
Upper limit threshold $\gamma$ & 0.5 & 2.1 \\
Nonlinear relationship threshold $\omega$ & 0.02 & 0.02 \\
Azimuth symmetry threshold $\tau$ & 0.23 & 0.26 \\
\hline
\end{tabular}

${ }^{*}$ The maximum response is defined as $54.74^{\circ}$

Table 2. The calibration factors of the two known trihedral corner reflectors.

\begin{tabular}{lccc}
\hline Cal. factors & & CR_1 & CR_2 \\
\hline Cross-Talk & $\tilde{t}_{h v}$ & $-3.586 \mathrm{e}-2, j 3.351 \mathrm{e}-2$ & $8.441 \mathrm{e}^{-}-j 3.306 \mathrm{e}-2$ \\
Cross-Talk & $\tilde{t}_{v h}$ & $2.859 \mathrm{e}-2, j 3.212 \mathrm{e}-2$ & $4.186 \mathrm{e}-2, j 4.242 \mathrm{e}-2$ \\
Cross-Talk & $\tilde{r}_{h v}$ & $-3.284 \mathrm{e}^{-2}, j 3.303 \mathrm{e}-2$ & $1.337 \mathrm{e}-2, j 2.421 \mathrm{e}-2$ \\
Cross-Talk & $\tilde{r}_{v h}$ & $3.624 \mathrm{e}-2, j 3.827 \mathrm{e}-2$ & $5.364 \mathrm{e}^{-2}, j 4.175 \mathrm{e}-2$ \\
Channel Imb. & $\tilde{t}_{v v}$ & $-0.9329, j 0.2889$ & $-0.9653, j 0.2435$ \\
Channel Imb. & $\tilde{r}_{h h}$ & $-0.9578,-j 0.4092$ & $-0.9262,-j 0.4123$ \\
Absolute Gain & $A e^{j \phi}$ & $10.6599 e^{j_{147.92}}$ & $10.9215 e^{j 19.76}$ \\
\hline
\end{tabular}

CR_2 due to the different distances between the SAR antenna and the two trihedral corner reflectors.

The originally observed and calibrated scattering matrixes based on the above seven calibration factors are shown in Table 3 . To assess the calibration accuracy, we normalized the observed and calibrated scattering matrixes using $\mathrm{HH}$ polarization, and the results are also shown in Table 3. For ideal trihedral corner reflectors such as CR_1 and CR_2, the normalized scattering matrixes should show an amplitude of $0 \mathrm{~dB}$ and a phase of 0 degrees in the diagonal terms, and a magnitude of $-\infty \mathrm{dB}$ and a phase of 0 degrees in the off-diagonal terms. Thus, equation (3) can be rewritten as :

$S_{i j}^{t r i} / S_{h h}^{t r i}=\left(\begin{array}{cc}\left(0 d B, 0^{\circ}\right) & \left(-\infty d B, 0^{\circ}\right) \\ \left(-\infty d B, 0^{\circ}\right) & \left(0 d B, 0^{\circ}\right)\end{array}\right)$

A comparison of the normalized scattering matrixes in Table 3 with equation (12) shows that the amplitudes and phases of the diagonal terms in the calibrated scattering matrixes were $0 \mathrm{~dB}$ and 0 degrees, respectively, both for CR_1 and CR_2 (Table 3), whereas the amplitudes of the lower-right diagonal terms $\left(O_{v v}^{t r i} / O_{h h}^{t r i}\right)$ in the originally observed scattering matrixes were not $0 \mathrm{~dB}$, especially for the phases (-40 degrees for CR_1, -38 degrees for CR_2). In comparison with the originally observed scattering matrixes, the phases of the off-diagonal terms in calibrated scattering matrixes also approached zero ( $\pm 1^{\circ}$ for CR_1, $\pm 5^{\circ}$ for CR_2), and the amplitudes became smaller (reduced by about $-5 \mathrm{~dB}$, to about -17 and $-15 \mathrm{~dB}$ for CR_1, -16 and $-15 \mathrm{~dB}$ for CR_2).

Figure 3 shows the originally observed and calibrated $\mathrm{co}^{-}$polarized signatures of CR_1 and CR_2 at the L-band. The theoretical signature of the trihedral corner reflector is shown in Fig. 3 (a). It can be seen that both originally observed co-polarized signatures of CR_1 and CR_2 showed noticeable distortions compared with their theoretical signatures (Figs. 3 (b) and (c)). If only the cross-talk calibration was carried out, the signatures of CR 1 and CR_2 still showed noticeable distortions (Figs. 3

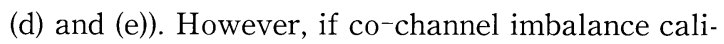
bration was carried out after the cross-talk calibra-

Table 3. Comparison of the known trihedral corner reflectors before and after calibration.

\begin{tabular}{ccc}
\hline Scattering matrix & CR_1 & CR_2 \\
\hline Observed $\left(\begin{array}{cc}O_{h h}^{t r i} & O_{h v}^{t r i} \\
O_{v h}^{t r i} & O_{v v}^{t r i}\end{array}\right)$ & $\left(\begin{array}{ccc}297.8223,-j 48.0359 & 8.6508, j 25.9525 \\
2.8946, j 26.0516 & 183.9426,-j 214.0422\end{array}\right)$ & $\left(\begin{array}{cc}-196.9212,-j 188.4817 & 0.0000,-j 22.7483 \\
5.5232, j 22.0927 & -265.6561,-j 26.2376\end{array}\right)$ \\
Calibrated $\left(\begin{array}{cc}S_{h h}^{t r i} & S_{h v}^{t r i} \\
S_{v h}^{t r i} & S_{v v}^{t r i}\end{array}\right)$ & $\left(\begin{array}{ccc}27.1806, j 0.0000 & 0.5518, j 1.188 \mathrm{e}^{-3} \\
0.7991,-j 1.305 \mathrm{e}^{-2} & 27.1806, j 0.0000\end{array}\right)$ & $\left(\begin{array}{cc}24.6469, j 0.0000 & 0.5596,-j 3.230 \mathrm{e}^{-2} \\
0.7083,-j 6.853 \mathrm{e}^{-2} & 24.6468, j 0.0000\end{array}\right)$ \\
Observed $\left(\begin{array}{cc}O_{h h}^{t r i} & O_{h v}^{t r i} \\
O_{v h}^{t r i} & O_{v v}^{t r i}\end{array}\right) / O_{h h}^{t r i}$ & $\left(\begin{array}{ccc}\left(0 d B, 0^{\circ}\right) & \left(-10.42 d B, 80.73^{\circ}\right) \\
\left(-10.61 d B, 92.82^{\circ}\right) & \left(-0.2894 d B,-40.16^{\circ}\right)\end{array}\right)$ & $\left(\begin{array}{cc}\left(0 d B, 0^{\circ}\right) & \left(-10.79 d B, 46.25^{\circ}\right) \\
\left(-10.78 d B, 60.29^{\circ}\right) & \left(-9.076 \mathrm{e}^{-2} d B,-38.10^{\circ}\right)\end{array}\right)$ \\
Calibrated $\left(\begin{array}{cc}S_{h h}^{t r i} & S_{h v}^{t r i} \\
S_{v h}^{t r i} & S_{v v}^{t r i}\end{array}\right) / S_{h h}^{t r i}$ & $\left(\begin{array}{ccc}\left(0 d B, 0^{\circ}\right) & \left(-16.92 d B, 0.12^{\circ}\right) \\
\left(-15.32 d B,-0.94^{\circ}\right) & \left(0 d B, 0^{\circ}\right)\end{array}\right)$ & $\left(\begin{array}{ccc}\left(0 d B, 0^{\circ}\right) & \left(-16.43 d B, 3.30^{\circ}\right) \\
\left(-15.40 d B,-5.53^{\circ}\right) & \left(0 d B, 0^{\circ}\right)\end{array}\right)$ \\
\hline
\end{tabular}




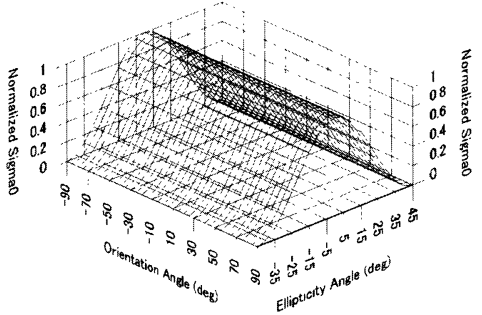

(a) The ideal co-polaized signature of the trihedral CR

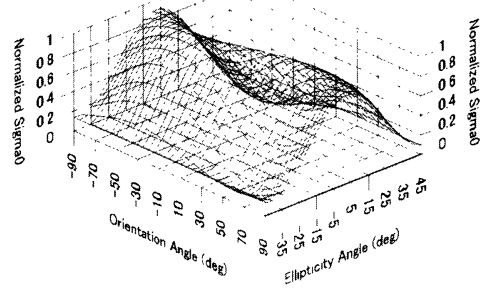

(b) Observed co-polarized signature of CR_1

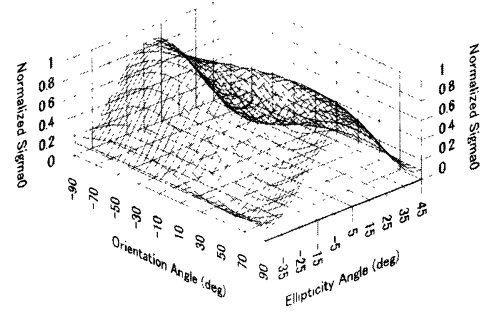

(d) After Cross-Talk Calibration of CR 1

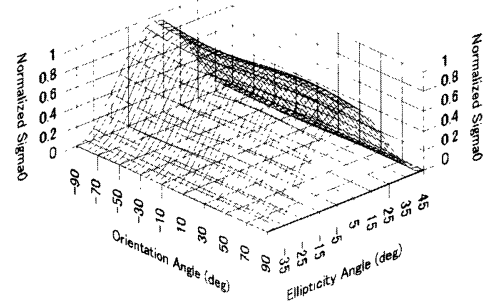

(f) After Co-channel Imbalance Cal. of CR_1

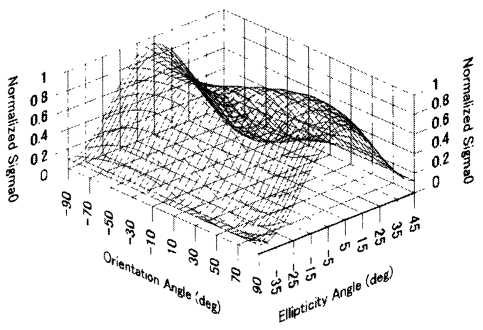

(c) Observed co-polarized signature of $\mathrm{CR} \_2$

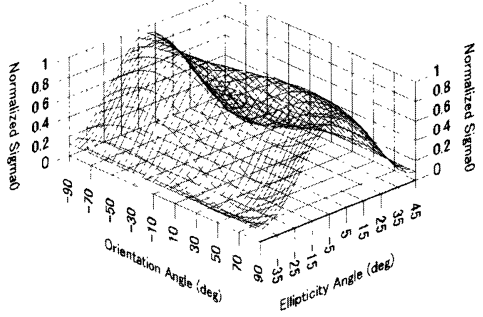

(e) After Cross-Talk Calibration of CR_2

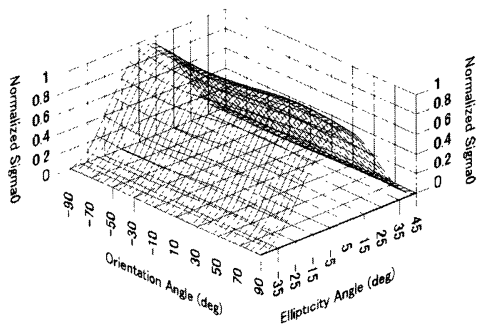

(g) After Co-channel Imbalance Cal. of CR_2

Figure 3 The result of applied Klein's algorithm to trihedral corner reflectors.

tion, the signatures of CR_1 and CR_2 showed close agreement with the theoretical signature (Figs. 3 (f) and $(g))$.

\section{Discussion}

In contrast with the POLCAL algorithm, Klein's algorithm can be used to calibrate PALSAR data, not only amplitude but also phase. This advantage allows us to use calibrated PALSAR data to estimate forest biomass based on Yamada's method. In addition, the use of Klein's algorithm can also allow us to omit the Faraday rotation included in the raw PALSAR data. Extracting the pixels that can satisfy the assumptions of Klein's algorithm (section 2.2.1) is a key step in the calibration procedure of PALSAR data. This is because the five thresholds will be determined by these pixels, and the seven calibration factors will be determined by the five thresholds. However, in conventional methods, an extensive flat surface was needed as a calibration site. It is difficult to find such areas where all pixels can satisfy the assumptions in section 2.2.1 with the exception of a few ideal flat calibration sites (e.g., the Goldstone calibration site). In this paper, we proposed to collect satisfactory pixels by selecting them from several relatively flat surface areas. Since we selected these pixels one by one, they were easier to obtain than an area in which all pixels can satisfy the assumptions, and thus a generally flat surface (e.g., a paddy field, plowed field, etc.) can also be selected as a calibration site. In addition, it is also difficult to determine the optimal thresholds for obtaining the calibration factors. To address this problem, we adjusted five thresholds repeatedly until the errors of CR_1 and CR_2 dropped to their 
minimum values.

It should be noted that the calibration factors were different between CR_1 and CR 2 due to the different distances between the SAR antenna and the two trihedral corner reflectors. Therefore, to calibrate a full scene composed of PALSAR polarimetric data, at least 5 trihedral corner reflectors are needed that are distributed at different distances from the SAR antenna to obtain a polynomial fit from the calibration factor of each trihedral corner reflector. The obtained polynomial fit is then used to calibrate a given pixel in the image.

Moreover, a $2.0 \mathrm{~m}$ trihedral corner reflector cannot be used for calibrating PALSAR onboard the satellite because it is too small compared with the spatial resolution of spaceborne PALSAR. Two larger trihedral corner reflectors with $4.0 \mathrm{~m}$ sides will be used to calibrate PALSAR onboard the "Daichi".

\section{Conclusions}

This paper proposes a calibration algorithm for both the amplitude and phase of full-polarimetric SAR data based on Klein's algorithm. A method of extracting pixels to satisfy the assumptions of Klein's algorithm in a general calibration site was also developed. In the pasture land, we obtained acceptable results both for amplitude and phase using two trihedral corner reflectors. However, to obtain the calibration factors for a full scene composed of PALSAR data, at least 5 trihedral corner reflectors are needed that are distributed at different distances from the SAR antenna.

\section{Acknowledgments}

The authors would like to thank the JPL/AIRSAR team for providing their valuable polarimetric SAR data. This study was supported by the New Energy and Industrial Technology Development Organization (NEDO) of Japan.

（受付日2006.8.31，受理日2007.1.10)

\section{References}

Cloude, S.R. and Papathanassiou, K.P., 1998, Polarimetric SAR interferometry, IEEE Transactions on Geosciences and Remote Sensing, vol. 36, no. 5, p.1551-1565.

Freeman, A., 1992, SAR Calibration : An Overview, IEEE Transactions on Geosciences and Remote Sensing, vol. 30, no. 6, p.1107-1121.

Freeman, A. and Saatchi S.S., 2004a, On the detection of Faraday Rotation in linearly polarized Lband SAR backscatter signatures, IEEE Transactions on Geosciences and Remote Sensing, vol. 42, no. 8, p.1607-1616.

Freeman, A., 2004b, Calibration of linearly polarized polarimetric SAR data subject to Faraday Rotation, IEEE Transactions on Geosciences and Remote Sensing, vol. 42, no. 8, p.1617-1624.

Fujita, M., 2003, Development of a Retrodirective PARC for ALOS/PALSAR Calibration, IEEE Transactions on Geosciences and Remote Sensing, vol. 41, no. 10, p.2177-2186.

Fujita, M., 2005, Polarimetric Calibration of Space SAR Data Subject to Faraday Rotation, IGARSS2005, Seoul, July 2005.

Kimura, H., 2005, Calibration of ALOS/PALSAR Polarimetric Data Affected by Faraday Rotation, IGARSS2005, Seoul, July 2005.

Klein, J.D., 1992, Calibration of complex polarimetric SAR imagery using backscatter correlations, IEEE Transactions on Aerospace and Electronic Systems, vol. 28, no. 1, p.183-194.

van Zyl, J.J., Burnette C.F., Zebker, H.A., Freeman A. and Holt J., 1990, POLCAL user's manual, Jet Propulsion Laboratory, p.31.

Yamada, H., Yamaguchi, Y. and KIM, Y., 2001, Polarimetric SAR interferometry for Forest Analysis Based on the ESPRIT Algorithm, IEICE TRANS. ELECTRON., vol. E84, no. 12, p.19171923.

Zebker, H.A. and Lou, Y., 1990, Phase calibration of imaging radar polarimeter Stokes matrices, IEEE Transactions on Geosciences and Remote Sensing, vol. 28, no. 2, p.246-252. 